Res., Soc. Dev. 2019; 8(2):e2082666

ISSN 2525-3409 | DOI: http://dx.doi.org/10.33448/rsd-v8i2.666

\title{
O impacto das facções têxteis no Seridó
}

The impact of sewing companies in Seridó

El impacto de las facciones textiles en el Seridó

Abigail Dantas Teixeira

Universidade Federal do Rio Grande do Norte, Brasil

E-mail: abigail.dantas@outlook.com

Ana Beatriz Silva Brito

Universidade Federal do Rio Grande do Norte, Brasil

E-mail: beatrizbrito1209@gmail.com

Carla Alessandra Porto do Nascimento

Universidade Federal do Rio Grande do Norte, Brasil

E-mail: shalom.carla@gmail.com

Jéssika Maria Santana Araújo

Universidade Federal do Rio Grande do Norte, Brasil

E-mail: jessika-santana1 @ hotmail.com

Josenilson Diniz Soares

Universidade Federal do Rio Grande do Norte, Brasil

E-mail: josenilsongabriel2009@hotmail.com

Wendell de Lira Bernardino

Universidade Federal do Rio Grande do Norte, Brasil

E-mail: wendellcn@gmail.com

Max Leandro de Araújo Brito

ORCID: https://orcid.org/0000-0003-2827-9886

Universidade Federal do Rio Grande do Norte, Brasil

E-mail: maxlabrito@gmail.com

Recebido: 05/10/2018 | Revisado: 18/10/2018 | Aceito: 29/10/2018 | Publicado: 01/11/2018

\section{Resumo}

O presente artigo tem por objetivo analisar a importância e o impacto econômico-financeiro da facções de confecções na região do Seridó. A metodologia utilizada foi qualitativa, através da aplicação de entrevistas com colaboradores dessas facções. Como resultado o estudo revela que esse ramo de atividade é uma importante alternativa para a geração de renda na referida 
região, onde é escasso o investimento da iniciativa privada. Por fim, o estudo conclui que o benefício das facções incide em grande parte da população, que anteriormente se encontrava ociosa e sem perspectiva de trabalho e renda, à margem do mercado de trabalho.

Palavras-chave: desenvolvimento; população; economia.

\begin{abstract}
The present article aims to analyze the importance and the economic and financial impact of garment factions in the Seridó region. Methodology to be applied, through the application of interviews with factional variables. As a result the result reveals that the industry is an important alternative for a generation of income in the region where the investment shortage is launched. Finally, the study concludes that the factions are largely concerned with being idle, with no prospect of work and income, on the margins of the labor market.
\end{abstract}

Keywords: development; population; economy.

\title{
Resumen
}

El presente artículo tiene por objetivo analizar la importancia y el impacto económicofinanciero de las facciones de confecciones en la región del Seridó. La metodología utilizada fue cualitativa, a través de la aplicación de entrevistas con colaboradores de esas facciones. Como resultado el estudio revela que esa rama de actividad es una importante alternativa para la generación de ingresos en la referida región, donde es escaso la inversión de la iniciativa privada. Por último, el estudio concluye que el beneficio de las facciones incide en gran parte de la población, que anteriormente se encontraba ociosa y sin perspectiva de trabajo y renta, al margen del mercado de trabajo.

Palabras clave: desarrollo; la población; economía.

\section{Introdução}

É de grande relevância buscar conhecer a influência econômica e social das facções na região do Seridó, tendo em vista que esta atividade tem se apresentado como alternativa para fomentar o mercado da referida região nos últimos anos, sendo ainda a causa da grande geração de emprego e uma das principais fontes de renda desses municípios, consequentemente, influenciando positivamente nos Índices de Desenvolvimento Humano Municipais.

O Seridó, ao longo de sua história, assim como tantas outras cidades interioranas, 
possui dificuldades de gerar recursos financeiros para girar sua economia de forma satisfatória. Fatores como estes, geram grande migração de sua população para cidades maiores em busca de trabalho e melhores condições de vida. A implantação e o fomento dessas facções busca o efeito oposto, que é proporcionar condições de vida adequadas às pessoas, de forma que estas não tenham que deixar suas cidades em busca de sustento, proporcionando assim, o crescimento mútuo, tanto da economia da região, quanto das famílias que ali residem e que estão direta ou indiretamente ligadas a estas facções.

Levando em conta o contexto apresentado acima, o presente estudo tem por objetivo analisar a importância e o impacto econômico-financeiro da facções de confecções na região do Seridó. A princípio é apresentado um referencial teórico da atividade têxtil seguido de metodologia, resultados e conclusão do estudo.

\section{Atividade têxtil}

Historicamente, o desenvolvimento econômico da região do Seridó iniciou-se a partir da pecuária e da agricultura de subsistência. Mas com o passar dos anos existiu a necessidade de outras fontes de economias, assim, surgindo a cotonicultura (produção de algodão) que dominou a economia do Seridó durante décadas (MEDEIROS, 2015).

Da região do Seridó Potiguar, a cotonicultura foi considerada uma das principais economias, mas em meados da década de 70 essa cultura começou a entrar em crise no mercado externo, afetando o preço dos produtos, além da proliferação de pragas que atingiu as lavouras de algodão, contribuindo para a decadência da atividade algodoeira. Hoje, a economia do povoado Currais Novos é centrada na atividade ceramista e a na indústria de vestimentas (MEDEIROS, 2015).

Das industrias de transformação, a atividade têxtil ocupa uma posição de destaque no estado do Rio Grande do Norte. Dos mais de 24 mil trabalhadores com carteira assinada em 2014, dados da Federação das Indústrias do Estado do Rio Grande do Norte (FIERN), uma boa parte desse número se dá pelo crescimento das facções que destacam-se na região do Seridó no interior do estado (CUNHA, 2015).

Com 21 mil peças diárias e 1.800 empregos diretos nas facções, a indústria de vestimentas possui grande influência no desenvolvimento socioeconômico da região. Destaque para os municípios de Acari, Jardim do Seridó e São José do Seridó onde possuem a maior concentração desses empreendimentos (CUNHA, 2015). 


\section{Metodologia}

O presente artigo é qualitativo. Segundo Flick (2009), a pesquisa qualitativa possui aspectos distintos daquela quantitativa, consistindo na adequada escolha de teorias e métodos, na consideração das diversas perspectivas dos participantes e na reflexibilidade dos pesquisadores, levando ao processo de produção de conhecimento. Quanto à natureza o estudo é trabalho científico original. Quanto aos objetivos a pesquisa é exploratória. Quanto aos procedimentos será estudo de campo.

Quanto ao objeto trata-se de um estudo de caso. Segundo Yin (2001, p.32): “o estudo de caso é uma investigação empírica de um fenômeno contemporâneo dentro de um contexto da vida real, sendo que os limites entre o fenômeno e o contexto não estão claramente definido". O estudo de caso permite lançar vistas sobre a realidade social, procurando organizar as informações dela obtidas.

A amostragem foi realizada por conveniência, por utilizar casos de maior facilidade de acesso, em consideração a limitação de tempo e de recursos.

A razão pela qual escolheu-se o referido caso, se dá pela importância da atividade têxtil no fomento da economia da região do Seridó. O motivo da escolha dos indivíduos entrevistados, ocorreu por se tratar de pessoas que estão inseridas no contexto das facções têxteis como colaboradores, sendo estes, pessoas indicadas para contribuir com informações fidedignas do ponto de vista do funcionário.

A técnica de coleta de dados foi a entrevista por meio de aplicativo de mensagens, que consiste na coleta de informações sobre determinada temática mediante o encontro entre duas pessoas, por meio de uma investigação social. Sobre a análise e interpretação dos dados:

\footnotetext{
A interpretação dos fenômenos e a atribuição de significados são básicas no processo de pesquisa qualitativa. Não requer o uso de métodos e técnicas estatísticas. O ambiente natural é a fonte direta para coleta de dados e o pesquisador é o instrumento-chave. (CUNHA, 2015, p. 34)
}

\section{Resultados}

A pesquisa foi realizada por meio do emprego de um aplicativo de mensagens instantâneas.

Os respondentes foram 4 sujeitos, a saber:

1. Sujeito A: 

a. Localização: Município de São Vicente
b. Sexo: Feminino
c. Idade: 45 anos
d. Cargo: Técnica (limpeza de peças)
e. Tempo de serviço: 5 anos

2. Sujeito B:
a. Localização: Município de São Vicente
b. Sexo: Masculino
c. Idade: 37 anos
d. Cargo: Técnico (revisão de peças)
e. Tempo de serviço: 5 anos

3. Sujeito C:
a. Localização: Município de São Vicente
b. Sexo: Feminino
c. Idade: 32 anos
d. Cargo: Costureira
e. Tempo de serviço: 3 anos

4. Sujeito D:
a. Localização: Município de São Vicente
b. Sexo: Feminino
c. Idade: 29 anos
d. Cargo: Costureira
e. Tempo de serviço: 3 anos

Ao serem perguntados sobre Importância das facções para o desenvolvimento da cidade (Quadro 1), os sujeitos abordaram o crescimento do comércio, nem sempre desenvolvido em cidades do interior do estado; a geração de empregos, que ocorre com a chegada das facções; e o desenvolvimento econômico, que é algo bastante procurado por pequenas cidades do Seridó.

Quadro 1: Importância das facções para o desenvolvimento da cidade

\begin{tabular}{|l|l|}
\hline \multicolumn{1}{|c|}{ Significado } & \multicolumn{1}{c|}{ Fala } \\
\hline \multirow{4}{*}{ Crescimento do comércio } & $\begin{array}{l}\text { Ajuda o comércio da cidade e auxiliando no desenvolvimento } \\
\text { econômico da mesma. (Sujeito A) }\end{array}$ \\
\cline { 2 - 2 } & $\begin{array}{l}\text { Grande importância para o comércio. (Sujeito D) } \\
\text { Griação de empregos que geram renda (Sujeito A) }\end{array}$ \\
\cline { 2 - 2 } & $\begin{array}{l}\text { Combate ao desemprego e geração de novos empregos formais } \\
\text { (Sujeito C) }\end{array}$ \\
\cline { 2 - 2 } & Antes das facções, os funcionários públicos eram os que \\
\hline
\end{tabular}




\begin{tabular}{|l|l|}
\hline & $\begin{array}{l}\text { movimentavam o comércio de São Vicente, hoje com os } \\
\text { funcionários das facções o comercio e outros negócios ficaram } \\
\text { fortalecidos e desenvolveram novas oportunidades de emprego. } \\
\text { (Sujeito B) }\end{array}$ \\
\hline Desenvolvimento econômico & $\begin{array}{l}\text { Movimentação da economia da cidade, além da diminuição do } \\
\text { número de pessoas em situação de baixa renda. (Sujeito C) }\end{array}$ \\
\hline
\end{tabular}

Fonte: Dados da pesquisa (2018)

Em relação as condições do ambiente de trabalho (Quadro 2), os entrevistados consideraram que o clima organizacional das facções é adequado, onde há bons relacionamentos e colaboração entre os funcionários, além de funcionarem em conformidade com a legislação que as compete.

\section{Quadro 2: Condições do ambiente de trabalho}

\begin{tabular}{|l|l|}
\hline \multicolumn{1}{|c|}{ Significado } & \multicolumn{1}{|c|}{ Fala } \\
\hline \multirow{4}{*}{ Bom clima organizacional } & $\begin{array}{l}\text { Ambiente bom e agradável, colaboração e bom relacionamento entre } \\
\text { os funcionários para aperfeiçoamento do trabalho de todos. (Sujeito } \\
\text { A) }\end{array}$ \\
\cline { 2 - 3 } & $\begin{array}{l}\text { Condições favoráveis e dignas de trabalho. Preocupação com a saúde } \\
\text { física e mental dos funcionários, além da disseminação de } \\
\text { informações para prevenção de problemas de saúde. Exigência e } \\
\text { fiscalização para o uso de EPIs. (Sujeito C) }\end{array}$ \\
\hline \multirow{3}{*}{ Atende as normas regentes } & $\begin{array}{l}\text { O local de trabalho é todo posto em acordo com as normas regentes, } \\
\text { totalmente regularizado e passa por vistorias e fiscalizações } \\
\text { necessárias. (Sujeito B) }\end{array}$ \\
\cline { 2 - 2 } & $\begin{array}{l}\text { Tudo dentro dos conformes, não há reclamações a declarar. (Sujeito } \\
\text { D) }\end{array}$ \\
\hline
\end{tabular}

Fonte: Dados da pesquisa (2018)

A partir das respostas relacionadas às mudanças na vida dos entrevistados e de sua família (Quadro 3), verificou-se que a qualidade de vida melhorou, aumentando o poder de compra, facilitando o acesso à educação e a aquisição de bens, além de proporcionar maior independência financeira.

\section{Quadro 3: Mudanças provocadas na vida dos funcionários}

\begin{tabular}{|c|c|}
\hline Significado & Fala \\
\hline \multirow{2}{*}{ Qualidade de vida } & $\begin{array}{l}\text { Qualidade de vida melhorou, vários bens adquiridos depois do } \\
\text { emprego. Ganho de recurso financeiro suficiente para abrir } \\
\text { um empreendimento. (Sujeito A) }\end{array}$ \\
\hline & $\begin{array}{l}\text { Melhoramento da qualidade de vida de muitas pessoas, novos } \\
\text { bens e imóveis adquiridos. Mais acesso à educação graças ao } \\
\text { aumento da renda. (Sujeito B) }\end{array}$ \\
\hline Independência financeira & Independência financeira do marido. (Sujeito A) \\
\hline \multirow{2}{*}{ Colaboração na renda da família } & $\begin{array}{l}\text { Contribuição para família e para a cidade por causa do } \\
\text { surgimento da renda individual. (Sujeito C) }\end{array}$ \\
\hline & $\begin{array}{l}\text { Compra da casa própria e mantem-se (financeiramente) por } \\
\text { esse emprego. (Sujeito D) }\end{array}$ \\
\hline
\end{tabular}

Fonte: Dados da pesquisa (2018)

Sobre o nível de satisfação proporcionada pelo trabalho (Quadro 4), os entrevistados estão satisfeitos pela oportunidade de estarem empregados e terem carteira assinada, 
recebendo os benefícios garantidos pelas leis trabalhistas, corroborando com o pensamento de Cunha (2015).

\section{Quadro 4: Nível de satisfação no trabalho}

\begin{tabular}{|c|c|}
\hline Significado & Fala \\
\hline \multirow{2}{*}{ Satisfação pela oportunidade de trabalhar } & $\begin{array}{l}\text { Apesar de ser um trabalho cansativo, possui } \\
\text { bastante satisfação e gratidão pela oportunidade } \\
\text { de emprego e benefícios para cidade advindo das } \\
\text { facções. (Sujeito A) }\end{array}$ \\
\hline & $\begin{array}{l}\text { Satisfação pela oportunidade de trabalhar na } \\
\text { própria cidade em que mora, sem haver a } \\
\text { necessidade de mudar de local para conseguir um } \\
\text { emprego. (Sujeito B) }\end{array}$ \\
\hline \multirow{2}{*}{$\begin{array}{l}\text { Satisfação por obtenção de renda fixa e } \\
\text { carteira assinada }\end{array}$} & $\begin{array}{l}\text { Satisfação pela obtenção de uma renda fixa, } \\
\text { carteira de trabalho assinada e pela oportunidade } \\
\text { de ajudar família e a cidade. (Sujeito C) }\end{array}$ \\
\hline & $\begin{array}{l}\text { Satisfação por receber os salários em dia e } \\
\text { também por ter direitos garantidos pela carteira } \\
\text { assinada. (Sujeito D) }\end{array}$ \\
\hline
\end{tabular}

Fonte: Dados da pesquisa (2018)

Ao final da entrevista, foi solicitado sugestões de melhorias que poderiam ser implantadas nas facções (Quadro 5). Foram indicados adequações na infraestrutura (como climatização), mais programas de capacitação para os superiores (principalmente para melhorar a gestão de conflitos) e, por fim, foi sugerida maior flexibilização na jornada de trabalho.

\section{Quadro 5: Sugestões de melhoria}

\begin{tabular}{|l|l|}
\hline \multicolumn{1}{|c|}{ Significado } & \multicolumn{1}{c|}{ Fala } \\
\hline \multirow{2}{*}{ Melhoria na infraestrutura } & $\begin{array}{l}\text { Climatização para deixar a temperatura do ambiente } \\
\text { mais agradável durante todo o dia. (Sujeito A) }\end{array}$ \\
\hline \multirow{2}{*}{ Programa de capacitação para os gestores } & $\begin{array}{l}\text { Necessidade de melhoria no tratamento aos } \\
\text { funcionários, mais humanizado. (Sujeito C) }\end{array}$ \\
\cline { 2 - 2 } & $\begin{array}{l}\text { Treinamento para os gerentes e supervisores, pois há } \\
\text { dificuldade de comunicação entre empregador, gerente } \\
\text { e supervisão assim trazendo desconforto e situações de } \\
\text { tensão para os demais funcionários. (Sujeito A) }\end{array}$ \\
\hline \multirow{3}{*}{ Flexibilização na jornada de trabalho } & $\begin{array}{l}\text { Jornada de trabalho com horários mais flexíveis, } \\
\text { tempo disponível para descanso, socialização e } \\
\text { alimentação. (Sujeito C) }\end{array}$ \\
\hline \multirow{2}{*}{ Sem sugestões } & Nenhuma sugestão no momento. (Sujeito B) \\
\cline { 2 - 2 } & Nenhuma sugestão no momento. (Sujeito D) \\
\hline
\end{tabular}

Fonte: Dados da pesquisa (2018)

\section{Conclusão}

Diante da pesquisa feita nesse trabalho, é perceptível o impacto sócio econômico gerado pela industrialização e terceirização da mão de obra na região do Seridó, no estado do Rio Grande do Norte. É notável na fala de algumas pessoas, nas entrevistas feitas na pesquisa 
deste trabalho, que com a vinda e o crescimento das facções do setor têxtil, houve mudanças significativas em seus municípios que proporcionaram um crescimento econômico e aumento da qualidade de vida.

Pelas limitações de tempo e orçamento, não foi possível fazer um pesquisa mais completa sobre esse impacto da indústria têxtil na região Seridó. Por exemplo, dados mais específicos como: a possibilidade de impactos negativos não foram adquiridos e nem foram coletados valores numéricos sobre o quanto de dinheiro é movimentado por consequência das facções.

Portanto, como é mencionado na introdução deste trabalho, é bastante importante procurar entender o funcionamento da facções e seus impactos na região, pois dessa forma torna-se possível a correção de problemas relacionados e no ampliamento das facções de forma sustentável e segura, assim consequentemente gerando mais empregos e renda para os pequenos municípios.

Para trabalhos futuros, sugere-se um campo de estudo mais abrangente, onde possa haver novas classes de pessoas entrevistadas, que estejam posicionados em distintos níveis dentro da organização.

\section{Referências}

BAUER, Martin W.; GASKELL, George. Pesquisa qualitativa com texto, imagem e som: um manual prático. Tradução de Pedrinho A. Guareschi. 7 ed. Petrópolis, RJ: Vozes, 2008.

CUNHA, Francisco André Medeiros da. Facções de costura no interior do RN: desafios e possibilidades. 2015 60f. Monografa (Graduação) Curso de Administração, Universidade Federal do Rio Grande do Norte, Currais Novos, 2015.Disponível em: < http://hdl.handle.net/123456789/1211> Acesso em 03 out. 2018.

FLICK, Uwe. Introdução à pesquisa qualitativa: Tradução de Joice Elias Costa. 3 ed. Porto Alegre: Artmed, 2009. 405 p.

LAKATOS, Eva Maria; MARCONI, Marina De Andrade. Fundamentos de metodologia científica: um manual prático. Tradução de Pedrinho A. Guareschi. 5ed. São Paulo: Atlas, 2003.

MEDEIROS, Geane Sabino de. O desenvolvimento econômico do povoado Currais Novos, localizado no município de Jardim do Seridó-RN, com destaque para a indústria de vestimentas. 2015. 60f. Monografia (Graduação) Curso de Geografia, Universidade Federal 
ISSN 2525-3409 | DOI: http://dx.doi.org/10.33448/rsd-v8i2.666

do Rio Grande do Norte, Caicó, 2015. Disponível em: < http://monografias.ufrn.br/jspui/handle/123456789/1835>. Acesso em: 03 out. 2018.

YIN, Robert K. Estudo de caso: Planejamento e métodos. 4 ed. Porto Alegre: Bookman, 2015. 